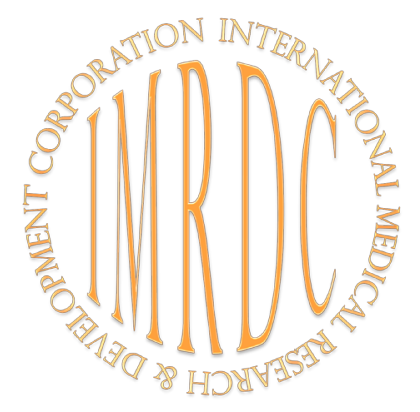

\title{
Role of the Immunological Markers in the Pathogenesis of Symptomatic Epilepsy in Children
}

\author{
Aliye E. Khalilova, $\mathrm{PhD}^{1}$; Yokudhon N. Madjidova, $\mathrm{PhD}, \mathrm{ScD}^{1 *}$; \\ Adolat $\mathrm{A}$. Ismailova, $\mathrm{PhD}, \mathrm{ScD}^{2}$ \\ ${ }^{1}$ Tashkent Medical Pediatric Institute \\ ${ }^{2}$ Republican Scientific Center of Immunology \\ Tashkent, Uzbekistan
}

\begin{abstract}
The objective of our study was to determine the profile of the spontaneous and mitogen-induced cytokine production in children with symptomatic epilepsy of different etiologies.

Materials and Methods: We examined 38 patients (aged between 3 and 18 years) with consequences of strokes (18.4\%), neuroinfections $(36.8 \%)$, neonatal brain injury (28.9\%), and brain development anomalies $(15.8 \%)$. The levels of spontaneous and mitogen-induced production of the main cytokines (IL-2, IL-6, IL-1 $\beta$, TNF $\alpha$ ) were determined by ELISA.

Results: We traced the decrease and/or inhibition in the production of the main regulatory cytokines of monocyte-macrophage profile (TNF $\alpha$, IL-1 $\beta$, IL-6) and adaptive immunity (IL-2) in children with symptomatic epilepsy; and we also revealed the insufficiency of the innate immunity factors in children, which was expressed in the suppression of the regulatory cytokine production, even with in vitro stimulation. the chronic course of the studied neurological conditions is a reflection of the condition of secondary immunodeficiency. (International Journal of Biomedicine. 2017;7(4):282-285.)
\end{abstract}

Key Words: children $\bullet$ symptomatic epilepsy $\bullet$ innate immunity $\bullet$ pro-inflammatory cytokines

\section{Introduction}

Approximately 50 million people worldwide have epilepsy, making it one of the most common neurological diseases globally. ${ }^{(1)}$ The social significance of epilepsy is determined by its prevalence, the young age of patients, the most severe consequences and complications, and inefficiency of treatment in $20 \%-25 \%$ of cases. The disease significantly limits life activity, and about $50 \%$ of patients eventually become disabled.(2)

In the pathogenesis of various diseases of the nervous system, an important role is assigned to immune mechanisms. Most researchers believe that the pathology of the central nervous system (CNS) and immune system can be viewed as the pathology of a single functional system that reflects signals from both the external and internal environments. It has been demonstrated ${ }^{(3,4)}$ that neuroimmune disorders are

*Corresponding author: Prof. Yokudhon N. Madjidova, PhD, ScD. Head of Department of Neurology, Pediatric Neurology and Medical Genetics of Tashkent Medical Pediatric Institute. Tashkent, Uzbekistan.E-mail: madjidoval@yandex.ru an important component in the pathogenesis of epilepsy. In particular, the role of inflammatory mediators in the development and progression of epilepsy is being actively studied. There are numerous experimental and clinical data on the role of proinflammatory factors in the pathogenesis of epilepsy, in particular, on the association of elevated levels of proinflammatory cytokines and acute-phase proteins with the risk of developing convulsive seizures..$^{(3,5-9)}$ In epilepsy, a chronic inflammatory process promotes the activation of microglia and astrogliosis, which is accompanied by damage to neurons, ${ }^{(7)}$ resulting in disrupted cytoplasmectonics of the hippocampus with the development of local neurodegeneration. ${ }^{(5)}$ The involvement of the inflammation process in the pathogenesis of epilepsy is vividly confirmed by the effectiveness of various anti-inflammatory drugs (corticosteroids, neurosteroids, immunoglobulins, etc.) in the treatment of forms of epilepsy that are resistant to traditional anticonvulsants. ${ }^{(6)}$

It is known that regulatory cytokines play an important role in the development, progression and prognosis of immunopathological processes. IL-1 $\beta$ is the most potent proinflammatory cytokine that is crucial in host-defense responses 
to infection and injury. ${ }^{(10)}$ This cytokine is an important mediator of the inflammatory response, and is involved in a variety of cellular activities, including cell proliferation, differentiation, and apoptosis. ${ }^{(11)} \mathrm{IL}-1 \beta$ is produced by activated macrophages, endothelial cells, B cells, and fibroblasts. IL-1 $\beta$ is responsible for a broad spectrum of immune and inflammatory responses, induces T-cell and B-cell activation, and consequently the synthesis of other pro-inflammatory cytokines (such as IFN- $\gamma$, IL-6 and TNF), and antibody production. This cytokine also induces the expression of itself in newly-arriving monocytes, thus reinforcing the overall process. ${ }^{(12)}$

In recent years, studies have shown that epileptic seizures can induce the production of cytokines, which in turn influence the pathogenesis and course of epilepsies. ${ }^{(13,14)}$ Since the etiology of symptomatic epilepsy varies, the question arises whether the etiology of the disease is important in increasing the levels of pro-convulsant cytokines, or whether the changes are nonspecific.

The objective of our study was to determine the profile of the spontaneous and mitogen-induced cytokine production in children with symptomatic epilepsy of different etiologies.

\section{Materials and Methods}

We examined 38 patients (aged between 3 and 18 years) with consequences of strokes $(18.4 \%)$, neuroinfections (36.8\%), neonatal brain injury (28.9\%), and brain development anomalies $(15.8 \%)$. The diagnosis of symptomatic epilepsy was made based on anamnestic data, the results of a brain MRI, and electroencephalographic data. Exclusion criteria were idiopathic forms of epilepsy, progressive and pharmacoresistant forms of epilepsy. Study of pro- and anti-inflammatory cytokine profiles was performed in blood plasma upon the patients' admission to the hospital and before treatment. The control group included 8 health children of the same ages as the study group.

The study was approved by the Tashkent Medical Pediatric Institute Ethics Committee. Written informed consent was obtained from the child's parents.

We determined the levels of spontaneous and mitogeninduced production of the main cytokines (IL-2, IL-6, IL-1 $\beta$, and $\mathrm{TNF} \alpha$ ) by ELISAusing an IFA-analyzer and the commercial test system Vector-Best (Novosibirsk, Russia) in the department of immunopathology and immunopharmacology of Republican Scientific Center of Immunology of RUz (2016-2017). For assessment of the mitogen-induced cytokine production, we used Cytokine Stimulus kit, the main components of which are a sterile medium and a complex mitogen (a mixture of lyophilized polyclonal activators that are used to induce cytokines in vitro).

Statistical analysis was performed using the statistical software «Statistica». (v6.0, StatSoft, USA) and Microsoft Excel 2007. Baseline characteristics were summarized as frequencies and percentages for categorical variables and as mean \pm SEM for continuous variables. The Mann-Whitney $\mathrm{U}$ Test was used to compare the differences between the two independent groups. A probability value of $\mathrm{P}<0.05$ was considered statistically significant.

\section{Results and Discussion}

As is known, the formation of the clinical stage of neuroimmunology was preceded by the accumulation of fundamental knowledge in this field, the study of immunopathogenesis of neurological diseases, and the achievements in the creation of new immunocorrecting drugs. In the study of immunopathogenesis of neurogenic diseases, an important role is assigned to the immune factors in the formation, development and progression of pathological processes. The immunopathological mechanism also plays a significant role in the chronicization of a number of diseases. In this connection, the role of immune mechanisms in the development of CNS diseases has been the subject of numerous studies. ${ }^{(6,7,9,15,16)}$ Of considerable interest are studies of the cytokine profile with the evaluation of the balance of proand anti-inflammatory cytokines as well as the production of mitogen-induced cytokine. This approach allows assessing the potential ability of the body to develop and progress the disease and has prognostic potential. In general, the study of cytokines with assessment of the cytokine-producing capacity of cells is an important criterion for assessment of nonspecific immunity. The main results of our studies are presented in Table 1.

Table 1.

The profile of the spontaneous and mitogen-induced cytokine production in children with symptomatic epilepsy of different etiologies

\begin{tabular}{|c|c|c|c|c|c|}
\hline Cytokine & $\begin{array}{c}\text { Control } \\
\text { group } \\
(\mathrm{n}-8)\end{array}$ & $\begin{array}{l}\text { Neuro- } \\
\text { infection } \\
(n=14)\end{array}$ & $\begin{array}{c}\text { Stroke } \\
(\mathrm{n}=7)\end{array}$ & $\begin{array}{c}\text { Neonatal } \\
\text { brain injury } \\
(n=11)\end{array}$ & $\begin{array}{c}\text { Brain } \\
\text { development } \\
\text { anomalies } \\
(n=6)\end{array}$ \\
\hline \begin{tabular}{|l|} 
IL-2 \\
spontaneous \\
production
\end{tabular} & $\begin{array}{l}17.2 \\
\pm 0.9\end{array}$ & $\begin{array}{c}9.5 \\
\pm 1.1\end{array}$ & $\begin{array}{c}8.0 \\
\pm 1.3^{*}\end{array}$ & $\begin{array}{c}8.0 \\
\pm 0.8^{*}\end{array}$ & $\begin{array}{c}13.3 \\
\pm 0.8^{*}\end{array}$ \\
\hline \begin{tabular}{|l|} 
IL-2 \\
mitogen- \\
induced \\
production \\
\end{tabular} & $\begin{array}{l}24.4 \\
\pm 2.4\end{array}$ & $\begin{array}{c}12.8 \\
\pm 1.9^{*}\end{array}$ & $\begin{array}{c}14.7 \\
\pm 4.6^{*}\end{array}$ & $\begin{array}{c}12.4 \\
\pm 1.9^{*}\end{array}$ & $\begin{array}{c}19.4 \\
\pm 1.1\end{array}$ \\
\hline \begin{tabular}{|l} 
Il-6 \\
spontaneous \\
production
\end{tabular} & $\begin{array}{l}14.5 \\
\pm 4.4\end{array}$ & $\begin{array}{l}20.2 \\
\pm 5.2\end{array}$ & $\begin{array}{l}16.5 \\
\pm 6.4\end{array}$ & $\begin{array}{c}26.5 \\
\pm 7.4^{*}\end{array}$ & $\begin{array}{c}27.5 \\
\pm 8.7 *\end{array}$ \\
\hline \begin{tabular}{|l} 
IL-6 \\
mitogen- \\
induced \\
production \\
\end{tabular} & $\begin{array}{c}195 \\
\pm 0.6\end{array}$ & $\begin{array}{c}148.3 \\
\pm 10.7^{*}\end{array}$ & $\begin{array}{c}163.3 \\
\pm 13.6^{*}\end{array}$ & $\begin{array}{l}164.7 \\
\pm 7.5^{*}\end{array}$ & $\begin{array}{c}123.5 \\
\pm 17.6^{*}\end{array}$ \\
\hline \begin{tabular}{|l} 
IL-1 $\beta$ \\
spontaneous \\
production
\end{tabular} & $\begin{array}{l}20.2 \\
\pm 9.3\end{array}$ & $\begin{array}{c}8.0 \\
\pm 2.3 *\end{array}$ & $\begin{array}{c}4.3 \\
\pm 0.2 *\end{array}$ & $\begin{array}{c}5.1 \\
\pm 1.1^{*}\end{array}$ & $\begin{array}{c}4.9 \\
\pm 0.3^{*}\end{array}$ \\
\hline \begin{tabular}{|l} 
IL-1 $\beta$ \\
mitogen- \\
induced \\
production \\
\end{tabular} & $\begin{array}{c}69.0 \\
\pm 10.2\end{array}$ & $\begin{array}{c}47.2 \\
\pm 4.1 *\end{array}$ & $\begin{array}{c}49.5 \\
\pm 3.0^{*}\end{array}$ & $\begin{array}{l}56.7 \\
\pm 6.5\end{array}$ & $\begin{array}{c}41.0 \\
\pm 9.6^{*}\end{array}$ \\
\hline \begin{tabular}{|l|} 
TNF-a \\
spontaneous \\
production
\end{tabular} & $\begin{array}{l}25.8 \\
\pm 5.6\end{array}$ & $\begin{array}{l}23.1 \\
\pm 5.1\end{array}$ & $\begin{array}{c}17.8 \\
\pm 2.4^{*}\end{array}$ & $\begin{array}{l}29.2 \\
\pm 7.6\end{array}$ & $\begin{array}{l}34.3 \\
\pm 3.1\end{array}$ \\
\hline
\end{tabular}

$*(P<0.05)$ - compared to control group

Thus, spontaneous and mitogen-induced production of IL-1b was significantly reduced in all groups of children with various neurological nosologies. The lowest value of 
spontaneous production of IL-1 $\beta$ was detected in the group of children with brain development anomalies. Moreover, spontaneous production of IL- $1 \beta$ was significantly decreased in all groups compared to control values, which indicates a certain deficiency of innate immune response. The analysis of the mitogen-induced production of IL- $1 \beta$ also revealed a significant reduction in IL- $1 \beta$ production in vitro, which also indicates the depletion of potential reserves of innate immunity, which in turn can be manifested by the functional insufficiency of the immune response.

One of the most important and well-studied lymphokines involved in the process of developing and enhancing the immune response is IL-2. Stimulation and production of IL-2 in the body supports the growth of T-lymphocytes. Therefore, it is called the T-cell growth factor. The spectrum of its biological action is wide. IL-2 induces proliferation of B-lymphocytes, activates cytotoxic T-lymphocytes, and stimulates natural killers (i.e. stimulates the cellular components of the immune system). IL-2 is an important pro-inflammatory cytokine that stimulates the proliferation and differentiation of activated T-lymphocytes into the effector Th-lymphocytes or cytotoxic T-cells. The main producers of IL-2 are T-helpers. An important result of the action of IL-2 on resting or stimulated antigen or mitogen cells is to ensure their proliferation. This biological activity of IL-2 defines it as a typical growth factor of cells of the lymphoid-myeloid complex.

Our results showed that spontaneous and mitogeninduced IL-2 production in all groups of children was significantly decreased in comparison with the control data. The lowest value of spontaneous and induced production of IL-2 was found in the group of children with birth trauma and with acute disorders of cerebral circulation. Thus, the low values of spontaneous and mitogen-induced IL-2 production indicate T-cell immunodeficiency.

Analysis of the TNF $\alpha$ level showed that spontaneous production of this cytokine was decreased in groups of children with inflammatory diseases of the brain and with acute impairment of cerebral circulation, but, at the same time, it was slightly increased in children with birth traumas and brain development abnormalities. It is known that an elevated $\mathrm{TNF} \alpha$ value indicates the severity of tissue damage on the background of the inflammatory reaction. In pathological conditions, microglia release large amounts of TNF $\alpha$; this de novo production of TNF $\alpha$ is an important component of the so-called neuroinflammatory response. ${ }^{(17,18)}$ In such situations, there is a need for a clinical interpretation of the pathological process.

The study of IL-6 level showed that spontaneous production of this cytokine was significantly increased in all groups of patients. Moreover, the greatest value of IL-6 was found in a group of children with birth trauma and brain development abnormalities, which also indicated the presence of severe damage to brain tissue. At the same time, the induced production of IL-6 was reduced, with the lowest values in the group of children with developmental anomalies, which indicates innate changes in cytokine regulation. It should be noted that the actions of IL- 6 are extremely diverse. On the spectrum of biological action, Il- 6 is close to IL- $1 \beta$ and TNF $\alpha$; it is involved in the development of inflammation, in immune reactions, and in the regulation of hematopoiesis. It also serves as a growth factor for plasma cells, and participates in intersystem interactions. IL-6 refers to cytokines that complete the development of the inflammatory reaction. ${ }^{(3,6)}$ In the immune system, the main targets of IL-6 are B-lymphocytes. IL-6 performs a certain, but unclear, role in the interaction of the immune and neuroendocrine systems. ${ }^{(14)}$

Thus, in the pathogenesis of symptomatic epilepsy, we traced the decrease and/or inhibition in the production of the main regulatory cytokines of monocyte-macrophage profile (TNF $\alpha$, IL-1 $\beta$, IL-6) and adaptive immunity (IL-2) in children; and we also revealed the insufficiency of the innate immunity factors in children, which was expressed in the suppression of the regulatory cytokine production, even with in vitro stimulation. These immunological disorders were accompanied by the suppression of IL-2 production. Thus, the chronic course of the studied neurological conditions is a reflection of the condition of secondary immunodeficiency. The results obtained on the role of immunological disorders in the pathogenesis of the disease can be used to optimize epilepsy treatment.

\section{Competing interests}

The authors declare that they have no competing interests.

\section{References}

1. WHO. Epilepsy. Fact sheet. Updated February 2017. Available from: http://www.who.int/mediacentre/factsheets/ fs $999 / \mathrm{en} /$

2. The International Classification of Functioning, Disability and Health (ICF). Geneva: WHO; 2001.

3. Vasilyeva OA, Gromov SA, Lipatova LV, Petrov AM. [Neuroantigenic landscape with various diseases of the central nervous system]. Neuroimmunology. 2005;3(2):164- 172. [Article in Russian].

4. Lisyaniy NI. [Classification of immune disorders in nerve diseases and their characteristics]. Neuroimmunology.2004; 2(2):61-62. [Article in Russian].

5. Evseev VA, Mikovskaia OI [Neuroimmunopathology: immunoaggression, dysregulation, adoptive immunotherapy prospects]. Zh Nevropatol Psikhiatr Im S S Korsakova. 2002; 102(5):60-64. [Article in Russian].

6. Lipatova LV, Serebryannaya NB, Sivakova NA, Kapustina T.V. Experience in the use of regulatory cytokines in the treatment of epilepsy. Neuroimmunology. 2015; 12(1-2):6364. [Article in Russian].

7. Lisyaniy N.I. Congenital and acquired immunity of the brain. Neuroimmunology.2015; 12(1-2:64. [Article in Russian].

8. Madjidova YoN, Khalilova AE, Sharipova NR. Revealing of risk factors symptomatic epilepsy at secondary encephalitis. Epilepsy and paroxysmal conditions. 2014; 6(4):50-54. [Article in Russian].

9. Hauser V. Descriptive epidemiology of epilepsy. In: Guseva EI, Geht AB, editors. Epilepsy: fundamental, clinical and social aspect. Moscow: APKIPPRO; 2013:53-83.

10. Dinarello CA. Biologic basis for interleukin-1 in disease. 
Blood. 1996;87(6):2095-147.

11. Vasilyeva OA, Lipatova LV, Gromov SA On the issue of neuroimmune disorders and their role in the treatment of patients with resistant forms of epilepsy. Siberian Herald of Psychiatry and Addiction Psychiatry. 2006; Suppl 41:64 - 66. [Article in Russian].

12. Bijak M, Dziedzic A, Synowiec E, Sliwinski T, SalukBijak J. Flavonolignans Inhibit IL1- $\beta$-Induced Cross-Talk between Blood Platelets and Leukocytes. Nutrients. 2017;9(9). pii: E1022. doi: 10.3390/nu9091022.

13. Sinha S, Patil SA, Jayalekshmy V, Satishchandra P. Do cytokines have any role in epilepsy? Epilepsy Res. 2008 Dec;82(2-3):171-6. doi: 10.1016/j.eplepsyres.2008.07.018. 14. Li G, Bauer S, Nowak M, Norwood B, Tackenberg
B, Rosenow F, et al. Cytokines and epilepsy. Seizure. 2011 Apr;20(3):249-56. doi: 10.1016/j.seizure.2010.12.005.

15. Khalilova AE, Majidova YoN. Epilepsy in children with stroke. Epilepsy and paroxysmal conditions. 2016; 8(4):3438. [Article in Russian].

16. Neveu PJ. Cerebral lateralization and the immune system. Int Rev Neurobiol. 2002;52:303-23.

17. Olmos G1, Lladó J1.Tumor necrosis factor alpha: a link between neuroinflammation and excitotoxicity. Mediators Inflamm. 2014;2014:861231. doi: 10.1155/2014/861231.

18. Montgomery SL, Bowers WJ.Tumor necrosis factor-alpha and the roles it plays in homeostatic and degenerative processes within the central nervous system.J Neuroimmune Pharmacol. 2012;7(1):42-59. doi: 10.1007/s11481-011-9287-2. 